\title{
Development of a continuous flow hydride generation laser-induced breakdown spectroscopic system: Determination of tin in aqueous environments ${ }^{2}$
}

\author{
Semira Ünal, Şerife Yalçın * \\ İzmir Institute of Technology, Faculty of Science, Chemistry Department, 35430 İzmir, Turkey
}

\section{A R T I C L E I N F O}

\section{Article history:}

Received 1 December 2009

Accepted 18 April 2010

Available online 29 April 2010

\section{Keywords:}

Volatile hydride

HG-LIBS

Environmental monitoring

Tin in aqueous samples

\begin{abstract}
A B S T R A C T
The design, construction and optimization studies of a continuous flow hydride generation laser-induced breakdown spectroscopic system, HG-LIBS, for the determination of tin in aqueous environments is presented. Optimization of the Laser Induced Breakdown Spectroscopy (LIBS) signal with respect to carrier gas flow rate, analyte, acid $(\mathrm{HCl})$ and reductant $\left(\mathrm{NaBH}_{4}\right)$ concentrations and flow rates was performed by using spectral emission intensity from the neutral $\mathrm{Sn}(\mathrm{I})$ line at $284.0 \mathrm{~nm}$ under atmospheric pressures. With flow rates of $5.0 \mathrm{~mL} / \mathrm{min}$ for $\mathrm{NaBH}_{4}$ and $2.5 \mathrm{~mL} / \mathrm{min}$ for $\mathrm{HCl}$, optimum $\mathrm{NaBH}_{4}$ and $\mathrm{HCl}$ concentrations were determined as $2.0 \%(\mathrm{w} / \mathrm{v})$ and $1.0 \%(\mathrm{v} / \mathrm{v})$, respectively. The hydride generation efficiency of the system was tested for tin hydride, stannane $\left(\mathrm{SnH}_{4}\right)$, by inductively coupled plasma mass spectrometer (ICP-MS). It was found that higher than $99 \%$ of the analyte was released into the gaseous phase. Upon optimization, the minimum detectable Sn concentration was found as $0.3 \mathrm{mg} / \mathrm{L}$ in water samples. That corresponds to more than two orders of increase in sensitivity compared to methods that employ common sample introduction techniques in liquids analysis by LIBS. Over 90\% recoveries were obtained from spiking experiments with river, tap and drinking water samples. Results illustrate potential use of the continuous flow HG-LIBS system for monitoring of Sn concentrations in aqueous environments.
\end{abstract}

(C) 2010 Elsevier B.V. All rights reserved.

\section{Introduction}

Arsenic, antimony, bismuth, germanium, lead, selenium, tellurium and tin are some elements that have environmental and technological importance. Quantification of these elements in environmental samples can be done by introducing aqueous solutions of these elements directly to atomic spectroscopic instruments, such as atomic absorption spectrometer, AAS, atomic emission spectrometer, AES, atomic fluorescence spectrometer, AFS, inductively coupled plasma mass spectrometer, ICP-MS and inductively coupled plasma optical emission spectrometer, ICP-OES. These elements can also be determined in the form of their volatile hydrides by using a type of sample introduction technique called hydride generation (HG) [1,2]. There is a great interest in the field of analytical chemistry in exploring the analytical capabilities of $\mathrm{HG}$ with respect to speciation analysis [3-5] and multi-element determinations [6,7] since its first use in 1968 by Holak [8].

Hydride generation is a chemical derivatization technique in which some elements of the periodic table mentioned above form

\footnotetext{
放 This paper was presented at the 5th Euro-Mediterranean Symposium on Lase Induced Breakdown Spectroscopy, held in Tivoli Terme (Rome), Italy, 28 September-1 October 2009, and is published in the Special Issue of Spectrochimica Acta Part B, dedicated to that Symposium.

* Corresponding author. Tel.: +90232 7507624; fax: +902327507509.

E-mail address: serifeyalcin@iyte.edu.tr (S.. Yalçın).
}

their volatile hydrides as indicated in the following reactions [1] when they react with strong reducing agents, such as sodium borohydride, $\mathrm{NaBH}_{4}$ and hydrochloric acid, $\mathrm{HCl}$.

$$
\begin{aligned}
\mathrm{NaBH}_{4}+3 \mathrm{H}_{2} \mathrm{O}+\mathrm{HCl} & \rightarrow \mathrm{H}_{3} \mathrm{BO}_{3}+\mathrm{NaCl}+8 \mathrm{H} \\
8 \mathrm{H}+\mathrm{E}^{+m} & \rightarrow \mathrm{EH}_{n} \uparrow+\mathrm{H}_{2} \text { (excess) } \quad \mathrm{E}^{+m}=\mathrm{Sn}, \mathrm{As}, \mathrm{Sb}, \mathrm{Pb} \ldots
\end{aligned}
$$

Here, $E$ is the desired metal, $m$ is the oxidation state of the metal and does not necessarily equal to the $n . \mathrm{EH}_{n}$ is the volatile metal hydride. In this technique, elements are separated from other accompanying materials in the form of gaseous hydrides and are introduced to the sample cell for atomization leaving the sample matrix in the liquid waste. Thus, spectral and chemical interferences can be eliminated. Therefore, significant increase in sensitivity, by 10 100 folds, over commonly used liquid sample introduction techniques has been reported [9-11].

The generation of volatile hydrides followed by atomic spectroscopic detection (AAS, AES, ICP-OES or ICP-MS) is the most common method of choice for the determination of toxic metals at trace levels of concentration, $(\mu \mathrm{g} / \mathrm{L}-\mathrm{ng} / \mathrm{L})$. These techniques provide high sensitivity but require laborious and time consuming sample collection steps for analyses to be conducted in the laboratory. In addition, the chemical identity of the sample may change during its delivery from the field to the laboratory. For this reason, there is a growing demand for rapid, real time, in situ and sensitive analysis techniques for 
environmental research applications. Laser Induced Breakdown Spectroscopy (LIBS) [12-14], is a very suitable technique to develop portable sensors and the utilization of this technique for the determination of environmental pollutants is increasing. There are several portable-LIBS sensors developed for environmental and industrial applications [15-18].

Applications of LIBS in bulk liquids [19-21], are few due to the difficulties experienced during analysis. Those difficulties are splashing, bubble formation and shock wave formation after focussing the laser beam on liquids. Liquid analysis by LIBS also suffers from poor signal quality, reduced plasma emission and low limits of detection due to shot to shot signal fluctuations. In order to overcome some of these difficulties, various approaches including: formation of the plasma on liquid surfaces [22], on droplets [23,24] on flowing-jet liquids [25] and use of double pulses for plasma formation [26,27] have been employed by several groups in LIBS community.

Here, we present design, construction and optimization studies of a continuous flow hydride generation sample introduction technique hyphenated with laser-induced breakdown spectroscopic detection (HG-LIBS) for the determination of hydride forming elements in aqueous samples, under atmospheric pressures. Yet, our work specifically focuses on optimization of the hydride generation conditions for the detection of tin ( $\mathrm{Sn}$ ) in standard and real water samples, however, this technique is also applicable to all other hydride forming elements like $\mathrm{As}, \mathrm{Se}, \mathrm{Sb}, \mathrm{Pb}, \mathrm{Bi}, \mathrm{Ge}$ and Te when suitable experimental conditions are satisfied.

Tin is a naturally occurring element and may be present in the environment in both organic and inorganic forms. Organic tin compounds are extremely toxic to marine organisms while inorganic tin compounds are regarded as non-toxic. Although, it is unknown at what level tin contributes to toxicity, the Agency for Toxic Substances and Disease Registry (ATSDR) of the United States [28] derived the oral minimum risk levels (MRL) of $0.0003 \mathrm{mg} / \mathrm{kg} / \mathrm{day}$ and $0.3 \mathrm{mg} / \mathrm{kg} / \mathrm{day}$ for tributyltin (TBT) and tin (II) chloride, respectively. The release of tin to the environment from anthropogenic sources exceeds tin release from geological sources 110 times. Inorganic tin is applied as coating a protective layer on other metals to prevent corrosion and also used in glass industry in the production of frost-free windshield. Organotin compounds are applied as fungicides, insecticides and as polymer additives in antifouling paint as a ship hull preservative. When control measures are inadequate excessive concentrations of tin and tin compounds may enter the environment by leaching from the consumer products and from the disposal of products in landfills. There is no value established by the WHO in drinking water guideline regarding tin and tin compounds due to low level of toxicity, however, according to Florida and Minnesota State regulations in the USA the MRL for tin in drinking water is given as $4.2 \mathrm{mg} / \mathrm{L}$ and $4.0 \mathrm{mg} / \mathrm{L}$, respectively [28].

Due to its environmental, technological and biological importance there are several studies in literature on the determination of tin by HG coupled to atomic spectroscopic detectors [9,29-31], however, studies on the measurement of tin in liquids by LIBS are few. In one of the studies on direct analysis of liquids by LIBS performed by Fichet et al. [32], LIBS was used to quantify trace amounts of 12 elements including tin, in water and oil samples of a nuclear plant. They have tried to eliminate a common problem of splashing, in liquids analysis by LIBS, by focussing the laser beam on the sample surface with a tilted angle of $15^{\circ}$. They reported a detection limit of $100 \mathrm{mg} / \mathrm{L}$ and $80 \mathrm{mg} / \mathrm{L}$ for tin in water and in oil samples, respectively.

The analytical capability of the liquid analysis by LIBS, in terms of detection limits, may be improved by converting relevant metal species to their metal hydrides. To our knowledge, one of the only two studies in the literature on the chemical generation of volatile hydrides followed by LIBS detection was carried out by Singh et al. [33]. They have used a batch type hydride generation method in which reductant and acidic analyte were mixed in a closed system. Measurements were performed in an evacuated cell, by mixing the hydrides with a carrier gas $\left(\mathrm{He}, \mathrm{N}_{2}\right.$ ) with predetermined concentrations and pressures. They have investigated the effect of the type of the carrier gas and ambient pressure on temporal emission behaviour of LIBS signal on tin ( $\mathrm{Sn}$ ) and arsenic (As) hydrides. They have observed that the neutral atomic emission of $\mathrm{Sn}$ at $284.0 \mathrm{~nm}$ decreases exponentially with time in $\mathrm{N}_{2}$ atmosphere while the signal increases logarithmically under identical experimental conditions in $\mathrm{He}$ atmosphere. Authors report no quantitative data for the detection limit of the studied elements.

The other study on HG-LIBS is a MSc thesis by Kunati [34] at Youngstown State University. In this study, HG-LIBS results for As, Sn and Te are compared with the results from HG-LIF (Laser Induced Fluorescence) and HG-ICP-AES. They report the same detection limit of $1.0 \mathrm{mg} / \mathrm{L}$ for three elements studied (As, Sn and Te) by HG-LIBS system equipped with Czerney-Turner monochromator and PMT detection.

Cheng et al. [35] has studied the measurement of metal hydrides; phosphine $\left(\mathrm{PH}_{3}\right)$, arsine $\left(\mathrm{AsH}_{3}\right)$ and diborane $\left(\mathrm{B}_{2} \mathrm{H}_{6}\right)$ concentrations, (1-400 mg/L), in helium gas standard at low pressures. The detection limits for phosphine, arsine and diborane were determined to be 1.0, 3.0 , and $1.0 \mathrm{mg} / \mathrm{L}$ by volume, respectively.

This paper focuses on the systematic investigation of the chemical and instrumental parameters of the HG-LIBS system for quantitative analysis of environmentally important elements that can form volatile hydrides. Results specifically obtained for tin hydrides, stannanes, $\mathrm{SnH}_{4}$, are presented in detail.

\section{Experimental}

The experimental set-up for continuous flow HG-LIBS system comprised of a hydride generation unit, a plasma cell and LIBS detection unit is schematically shown in Fig. 1. Here, volatile hydrides generated in a continuous flow reaction system are carried through a Teflon tubing into a five armed Teflon plasma cell in which laser pulses of $150 \mathrm{~mJ}$ energy are used to create plasma. Spectral lines emitted from the plasma are collected at $90^{\circ}$ angle with respect to incoming laser beam and imaged by a pair of plano-convex lenses onto a $600 \mu \mathrm{m}$ diameter fiber optic cable and transferred into an echelle spectrograph equipped with an ICCD detector.

\subsection{Hydride generation unit}

A continous flow hydride generation (HG) unit, given in Fig. 2, utilizes a four-channel peristaltic pump (Longer Precision) with adjustable speed to deliver acidified analyte and $\mathrm{NaBH}_{4}$ solution to a 3-way PTFE connector

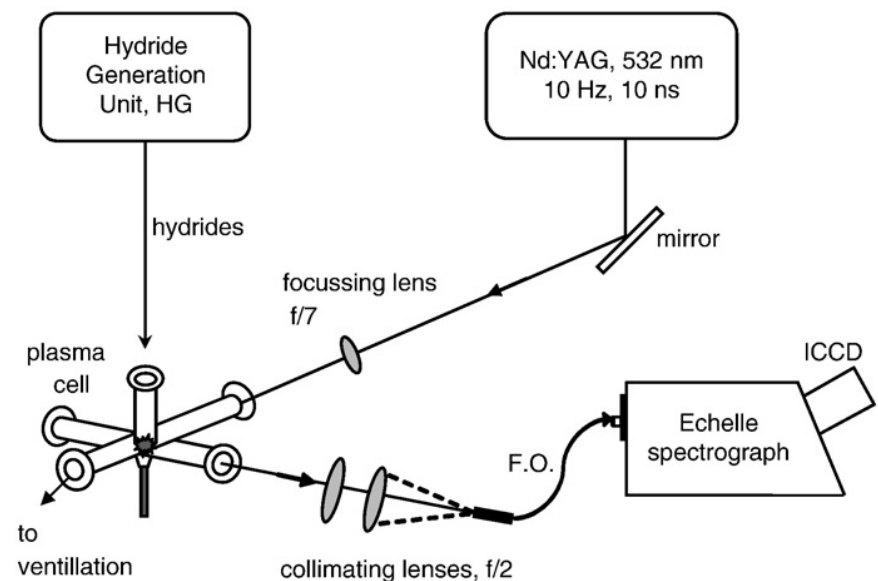

Fig. 1. Schematic diagram of the HG-LIBS set-up. Volatile hydrides from the hydride generation system are carried through the five armed Teflon plasma cell. $150 \mathrm{~mJ}$ laser pulses are used to create plasma. Spectral emission from the plasma is collected by a pair of plano-convex lenses ( $10 \mathrm{~cm}$ F.L.), imaged onto the fiber optic cable and transferred into the spectrograph to be detected. 


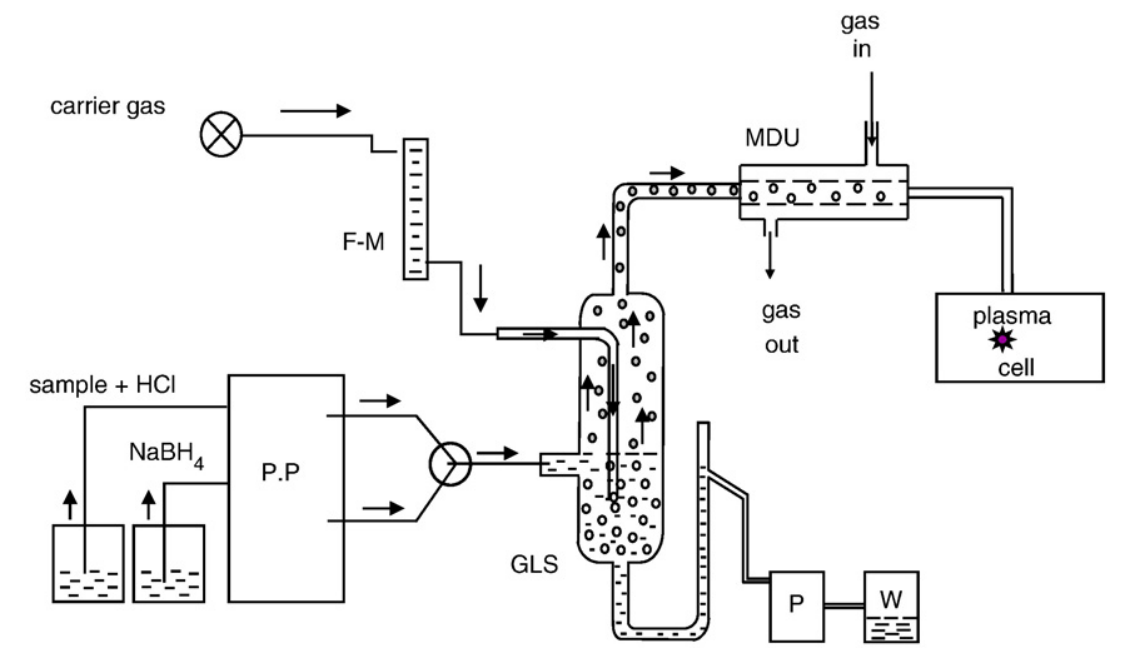

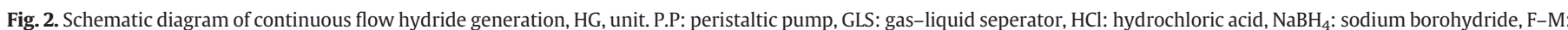
flow meter, MDU: membrane drying unit, P: pump, W: waste.

(Supelco) where hydride generation reaction starts. Gaseous hydrides produced from this reaction were first carried into a U-type gas-liquid separator, GLS, separated from the liquid waste by a continuous flow of carrier gas $\left(\mathrm{N}_{2}\right)$, and then carried into a nafion membrane dryer (Perma Pure). Inert purge gas, $\mathrm{N}_{2}$ or $\mathrm{Ar}$, flowing over the exterior surface of the membrane tubing in counter-current direction with respect to sample flow was employed to remove water vapor from the hydrides. After passing the drying unit, hydrides were introduced into the sample/plasma cell from the top for plasma formation. One side arm of the cell was used for incoming laser beam another one situated at $90^{\circ}$ was used for the collection of plasma emission. It is a closed system and these two arms were equipped with quartz windows. The remaining two arms were closed by connecting one to a ventillation system through a vacuum pump and another one to a pressure gauge, respectively. The system was under atmospheric pressures due to continuous flow of reagents during the experiments. Waste solution was pumped out from the GLS by using another peristaltic pump (ISMATEC, Germany) at a controlled flow rate. The carrying and drying purge gas flow rates were controlled by using two separate flow controllers (Cole Palmer). Five armed plasma cell machined from Teflon material provides chemical inertness for this corrosive environment.

\subsection{LIBS set-up}

A Q-switched Nd:YAG laser (Spectra Physics, LAB170-10) at $532 \mathrm{~nm}$, with a pulse width of $10 \mathrm{~ns}$ and a repetition rate of $10 \mathrm{~Hz}$ was used to form plasma from tin hydrides $\left(\mathrm{SnH}_{4}\right)$. Laser pulse energy measurements were performed by a power/energy meter (Ophir, Nova II). The laser beam was focused inside the 5 armed Teflon cell, by using $175 \mathrm{~mm}$ focal length (f/7) plano-convex lens and the plasma emission was collected at an angle of $90^{\circ}$ with respect to incoming laser beam by means of two $100 \mathrm{~mm}$ focal length (f/2) plano convex lenses. The collected light was launched onto an optical fiber (Ocean Optic, $600 \mu \mathrm{m}$ diameter) coupled to an echelle type spectrograph (ME5000, Andor Inc. $f=195 \mathrm{~mm}$ ), equipped with a gated, image intensified charge coupled detector, ICCD (iStar DH734, Andor Inc.). The spectrograph and detection system's spectral range is between 200 and $850 \mathrm{~nm}$ with $0.08 \mathrm{~nm}$ resolution at $400 \mathrm{~nm}$. Wavelength calibration of the spectrograph was done by using $\mathrm{Hg}-\mathrm{Ar}$ spectral calibration lamp. The detector gain was kept at 100 with $10 \mu \mathrm{s}$ delay and 3 ms gating time, for almost all experiments.

\subsection{Standards and reagents}

Tin standard solutions were prepared daily from stock Sn solution ( $1000 \mathrm{mg} / \mathrm{L}$ in $20 \% \mathrm{HCl}$, High-Purity Standards) through appropriate dilutions with ultra pure water. Standard and real samples were acidifed with concentrated $\mathrm{HCl}$ to reach a desired acid concentration. All reagents were of analytical grade or higher purity. Sodium borohydride solutions were prepared by dissolving appropriate amount of $\mathrm{NaBH}_{4}$ powder (Sigma-Aldrich) in $1.0 \%$ (w/v) $\mathrm{NaOH}$ (Riedel-de Haën) for stabilization and used without filtration.

River Water Reference Material for trace metals, SLRS-4, was obtained from NRC, Canada, Ottowa and used without dilution. No detectable tin concentration was listed among 22 metals for which certified values are in the range of low ppb levels. Tap water was from İzmir-Urla municipal water supply and drinking water was a bottled spring water (Pınar) from Aydın, Turkey.

\section{Results and discussion}

Instrumental and chemical parameters of HG-LIBS system were systematically studied in order to provide high efficiency of hydride generation and LIBS detection for tin in aqueous environments. Optimization procedures for each parameter are given in detail below and optimized conditions used throughout the experiments are tabulated in Table 1.

\subsection{Optimization of instrumental parameters for HG-LIBS}

In order to maximize LIBS signal, some of the key parameters, like laser energy, detector delay time, gate time and gain were studied first. The percentage of the pulse energy deposited into the Sn hydride, stannane, plasma was quantified from pulse energy measurements between 80 and $175 \mathrm{~mJ} /$ pulse laser energy range. This energy range corresponds to average power density of 1.9$4.2 \mathrm{TW} / \mathrm{cm}^{2}$ for a diffraction limited beam size of $23 \mu \mathrm{m}$. As it is shown in Fig. 3(a), the plasma absorbs $65 \%$ of the input pulse energy when $80 \mathrm{~mJ} /$ pulse laser energy is applied. Increasing input laser energy to $175 \mathrm{~mJ} /$ pulse, percent absorption increases only up to $76 \%$. This so called 'saturation effect' has been observed previously by some other researchers [36,37]. They explained that, after sufficient energy is deposited for ionization, excess energy is used to enlarge the size of the plasma rather than increasing the plasma temperature or electron density. Within the content of this study, temperature and electron density calculations have not been performed, however, the change in the physical size of the plasma was evident as the laser energy increases during the experiments.

Spectral line intensity measurements for $284.0 \mathrm{~nm}$ neutral tin, Sn (I), emission as a function of laser pulse energy were performed and presented in Fig. 3(b). From $80 \mathrm{~mJ}$ to $100 \mathrm{~mJ}$ pulse energy, LIBS signal 
Table 1

Optimum chemical conditions ${ }^{\mathrm{a}}$ for the generation and detection of tin hydrides, $\mathrm{SnH}_{4}$, with HG-LIBS system.

\begin{tabular}{ll}
\hline $\mathrm{NaBH}_{4}$ conc. & $2.0 \%(\mathrm{w} / \mathrm{v})$ in $1.0 \% \mathrm{NaOH}(\mathrm{w} / \mathrm{v})$ \\
$\mathrm{NaBH}_{4}$ flow rate & $5.0 \mathrm{~mL} / \mathrm{min}$ \\
$\mathrm{HCl}$ conc. & $1.0 \%(\mathrm{v} / \mathrm{v})$ \\
Acidified sample flow rate & $2.5 \mathrm{~mL} / \mathrm{min}$ \\
Carrier gas $\left(\mathrm{N}_{2}\right)$ flow rate & $137 \mathrm{~mL} / \mathrm{min}$ \\
\hline
\end{tabular}

a $150 \mathrm{~mJ} /$ pulse energy, Td: $10 \mu \mathrm{s}, \mathrm{Tg}$ : $3 \mathrm{~ms}$ and $5.0 \mathrm{mg} / \mathrm{L} \mathrm{Sn}$ solution were used.

intensity was increased more than two times. However, after $100 \mathrm{~mJ} /$ pulse energy, no significant change in LIBS signal intensity was observed. Also, at high laser energies, RSD of the signal calculated for seven sequential measurements was quite high, ranging from $20 \%$ to $25 \%$, due to increased shot to shot variation. However, experiments were performed at $150 \mathrm{~mJ} /$ pulse laser energies, to ensure complete breakdown for all laser shots.

In order to determine optimum time interval for detecting tin lines from the luminous plasma, detector gating parameters and gain were optimized from time resolution experiments. Typically, long integration time $(\mathrm{Tg})$ is preferred with plasmas that have a long lifetime to maximize signal. In this work, $10 \mu$ s delay time, $\mathrm{Td}, 3 \mathrm{~ms}$ gate time, $\mathrm{Tg}$, and a gain setting of 100 were found as optimum conditions for spectral emission measurements of tin by LIBS. A representative 10 shot accumulation spectra acquired from the tin hydrides, stannanes, by HG-LIBS system was given in Fig. 4 . The peaks labeled between 260 and $330 \mathrm{~nm}(270.65 \mathrm{~nm}, 284.0 \mathrm{~nm}, 286.3 \mathrm{~nm}, 300.9 \mathrm{~nm}, 303.4 \mathrm{~nm}$,

(a)

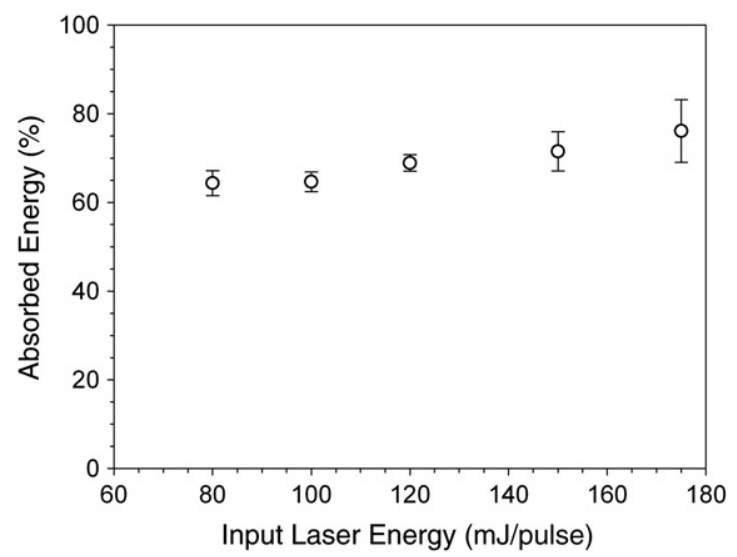

(b)

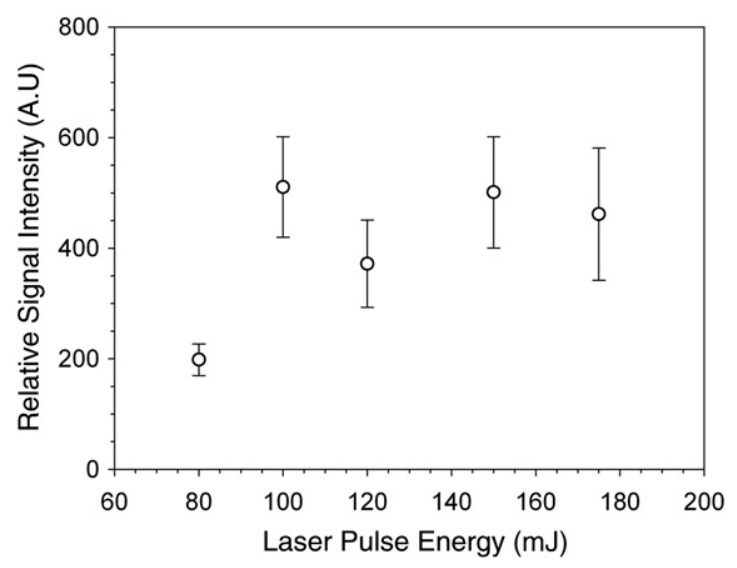

Fig. 3. (a) Absorbed energy by the Sn plasma with respect to input pulse energy. (b) Variation of $\mathrm{Sn}(\mathrm{I})$ line intensity at $284.0 \mathrm{~nm}$ as a function of laser pulse energy. Td: $10 \mu \mathrm{s}, \mathrm{Tg}$ : $3 \mathrm{~ms}$, solution with $10.0 \mathrm{mg} / \mathrm{L}$ Sn concentration was used. Error bars represent variation in signal intensity for seven replicate measurements.
$317.50 \mathrm{~nm}$ and $326.2 \mathrm{~nm}$ ) correspond to neutral emission lines of Sn (I) for the experimental conditions selected and well consistent with NIST atomic spectral database.

For quantitative analysis of $\mathrm{Sn}$ in aqueous solutions, the resonance line at $284.0 \mathrm{~nm}$ was chosen. The spectral range between 330 and $580 \mathrm{~nm}$ was not represented in the figure, due to the presence of no valuable information regarding tin analysis. The second part of the spectrum between 580 and $665 \mathrm{~nm}$, contains well resolved sodium doublet at $589.0 \mathrm{~nm}$ and $589.6 \mathrm{~nm}$ and hydrogen alpha line at $656.3 \mathrm{~nm}$ with relatively high signal strength. Excess amount of hydrogen is produced from the hydride generation reaction as well as from the decomposition of tin hydride in the plasma and also from the moisture content of the hydrides. Strong sodium lines indicate $\mathrm{Na}$ transport from the GLS to the plasma cell along with the hydrides.

\subsection{Optimization of chemical parameters for HG-LIBS}

Hydride generation conditions; like concentration, flow rate of reagents and carrier gas were optimized individually in trials in order to maximize signal to noise ratio for the determination of $\mathrm{Sn}$ in aqueous environments. During optimization of chemical parameters, instrumental parameters like laser energy, detector delay and gate times were kept fixed at optimum conditions as $150 \mathrm{~mJ}, 10 \mu \mathrm{s}$ and $3 \mathrm{~ms}$, respectively. Analytical signals were obtained from the average of minimum 5 replicate measurements, each constitute an accumulation of 10 laser shots of $150 \mathrm{~mJ} /$ pulse energy. In most of the optimization experiments, tin solutions with $5.0 \mathrm{mg} / \mathrm{L}$ concentration were used.

\subsubsection{Effect of $\mathrm{NaBH}_{4}$ and $\mathrm{HCl}$ concentration on HG-LIBS signal}

In order to investigate the effect of reductant concentration on the efficiency of tin hydride generation for LIBS detection, $\mathrm{NaBH}_{4}$ solutions between $0.1 \%$ and $10.0 \%(\mathrm{w} / \mathrm{v})$ concentrations were prepared and made alkaline with $1.0 \%(\mathrm{w} / \mathrm{v}) \mathrm{NaOH}$ for stability. As can be seen in Fig. 5(a) there is a marked increase in tin hydride production with increasing $\mathrm{NaBH}_{4}$ concentration up to $2.0 \%$ and maximum LIBS signal was obtained at $5.0 \% \mathrm{NaBH}_{4}$ concentration. In cases where better detection limits are not required, $2.0 \%(\mathrm{w} / \mathrm{v}) \mathrm{NaBH}_{4}$ concentration with slightly lower sensitivity was employed in our experiments in order to reduce $\mathrm{NaBH}_{4}$ consumption. The analyte and reductant flow rates of 2.5 and $5.0 \mathrm{~mL} / \mathrm{min}$ were used, respectively. $\mathrm{HCl}$ concentration was kept at $1.0 \%$ and $\mathrm{N}_{2}$, as a carrier gas, with a flow rate of $137 \mathrm{~mL} / \mathrm{min}$ was used throughout the experiments.

The type and concentration of an acid has a considerable effect on the efficiency of hydride generation. Several reports [9] exist on the use of acetic, sulfuric, tartaric, hydrofluoric and nitric acid for a vigorous reaction with $\mathrm{NaBH}_{4}$, but hydrochloric acid, $\mathrm{HCl}$, is the most widely used one. Optimization of acid concentration was performed in the range of $0.1 \%-2.5 \% \mathrm{HCl}(\mathrm{v} / \mathrm{v})$ concentrations, while keeping $\mathrm{NaBH}_{4}$ solution at $2.0 \%(\mathrm{w} / \mathrm{v})$ concentration. As shown in Fig. 5(b), relative intensity of the LIBS signal has increased upto $1.0 \% \mathrm{HCl}$ concentration and showed a little variation between $1.0 \%$ and $2.5 \%$ concentration. The maximum LIBS signal from $5.0 \mathrm{mg} / \mathrm{L}$ Sn solution at $284.0 \mathrm{~nm}$ was obtained from $2.0 \% \mathrm{HCl}(\mathrm{v} / \mathrm{v})$ concentration, however, $1.0 \% \mathrm{HCl}$ concentration with a slightly lower sensitivity was selected as optimum acid concentration for hydride generation to avoid excessive acid consumption.

\subsubsection{Effect of sample and carrier gas flow rates on HG-LIBS signal}

Sample and reagents were introduced into the GLS continually by using a peristaltic pump. The flow rates of acidified sample and reductant were adjusted by selecting pump tubings of proper sizes, at a fixed pump rate. The effect of sample flow rate on Sn signal intensity was shown in Fig. 6(a). Typically, increasing sample flow rate increases tin signal intensity due to increased amount of analyte loading into the GLS. As optimized, reductant and acid concentrations 


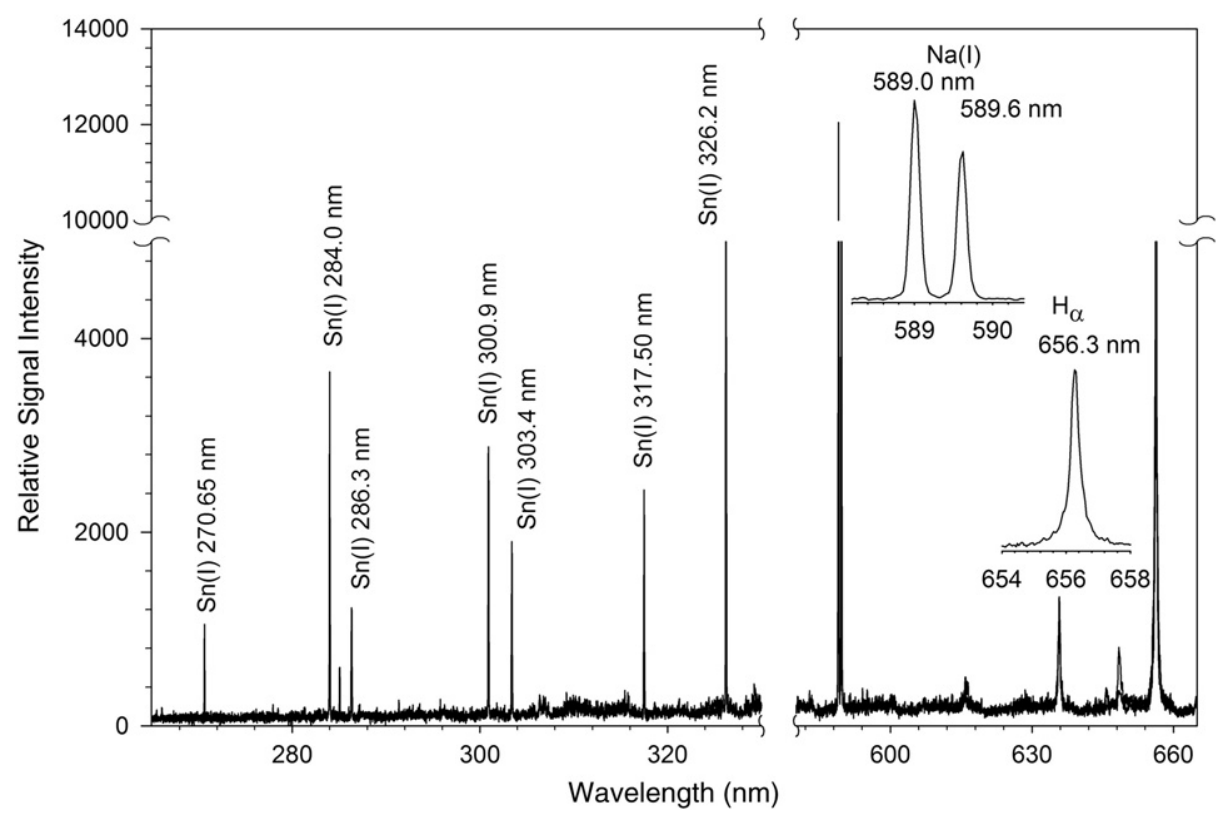

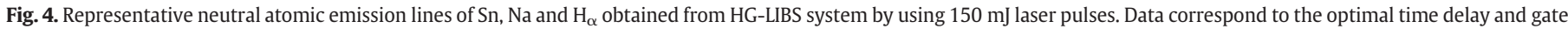
width. Td: $10 \mu \mathrm{s}, \mathrm{Tg}$ : $3 \mathrm{~ms}$, was used. $10.0 \mathrm{mg} / \mathrm{L} \mathrm{Sn}$ in $1.0 \% \mathrm{HCl}, 2.0 \%(\mathrm{w} / \mathrm{v}) \mathrm{NaBH}_{4}$ in $1.0 \%(\mathrm{w} / \mathrm{v}) \mathrm{NaOH}$ and $137 \mathrm{~mL} / \mathrm{min}$ carrier gas $\left(\mathrm{N}_{2}\right)$ flow rate were utilized.

(a)

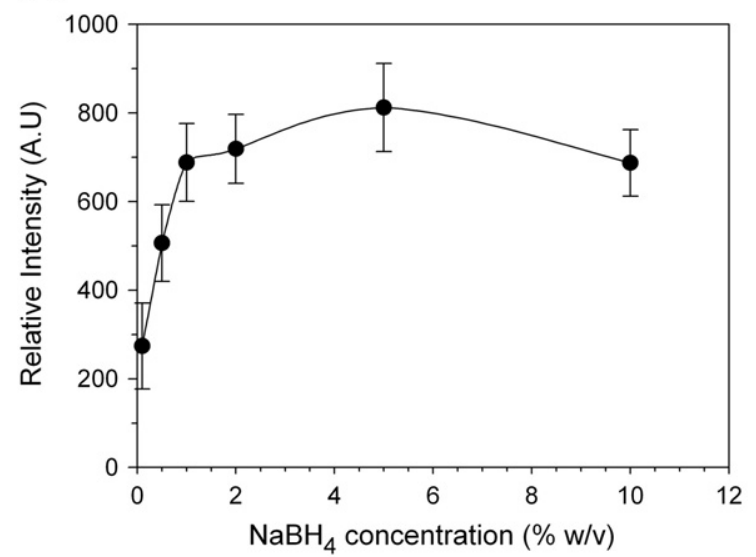

(b)

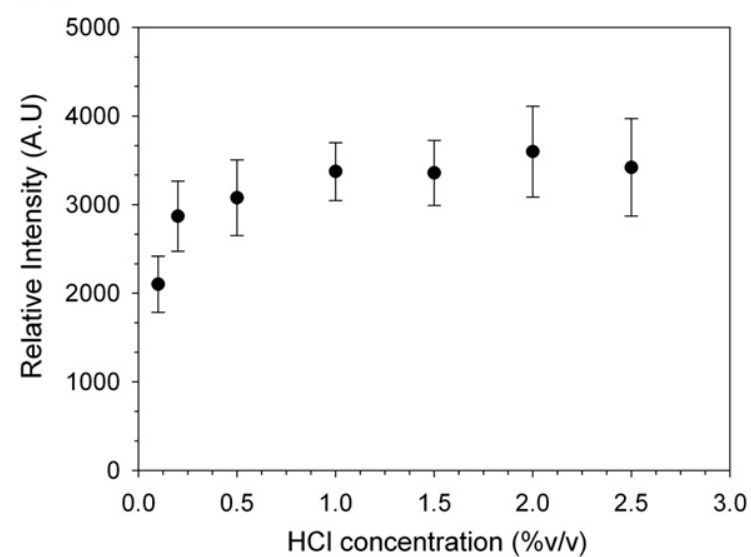

Fig. 5. Effect of concentration of $\mathrm{NaBH}_{4}$ (a) and $\mathrm{HCl}$ (b) solution on Sn signal intensity. During the optimization of $\mathrm{NaBH}_{4}, 1.0 \%(\mathrm{v} / \mathrm{v}) \mathrm{HCl}$ and during the optimization of $\mathrm{HCl}$ $2.0 \%(\mathrm{w} / \mathrm{v}) \mathrm{NaBH}_{4}$ were used. LIBS signal was obtained from $5.0 \mathrm{mg} / \mathrm{L}$ Sn solution at $284.0 \mathrm{~nm}$. 10 shot accumulation with Td: $10 \mu \mathrm{s}, \mathrm{Tg}: 3 \mathrm{~ms}$ and laser energy of $150 \mathrm{~mJ} /$ pulse is used. $\mathrm{N}_{2}$ was used as a carrier gas with a flow rate of $137 \mathrm{~mL} / \mathrm{min}$. of $5.0 \% \mathrm{NaBH}_{4}$ and $1.0 \% \mathrm{HCl}$ were used for the observation of the effect of sample and carrier gas flow rate on LIBS signal strenght. There is a sharp increase in signal intensity when sample flow rate increases from $1.0 \mathrm{~mL} / \mathrm{min}$ to $2.5 \mathrm{~mL} / \mathrm{min}$. Beyond this value, the variation in tin signal is not significant therefore $2.5 \mathrm{~mL} / \mathrm{min}$ sample flow rate was selected as optimum.

In $\mathrm{HG}$ systems, the carrier gas, $\mathrm{N}_{2}$ or $\mathrm{Ar}$, is used to transport volatile hydrides from the GLS to the atomization cell. Therefore, the carrier gas flow rate is very critical in terms of efficient transportation and atomization conditions. The variation in signal intensity with respect to carrier gas flow rate for our experimental set-up is given in Fig. 6 (b). The optimum carrier gas flow rate was obtained at $137 \mathrm{~mL} / \mathrm{min}$ $\mathrm{N}_{2}$. At flow rates less than this value the signal is low, which may be originating from the loss of the hydrides due to the condensation on inside walls of both the GLS and Teflon tubing that connects GLS to plasma cell.

At flow rates higher than $137 \mathrm{~mL} / \mathrm{min} \mathrm{N}_{2}$, signal intensity starts to decrease. This can be attributed to fast flushing of the tin hydrides by the $\mathrm{N}_{2}$ gas from the sample cell so that the residence time of tin atoms decreases. Also, at high flow rates of the carrier gas, the ratio of the number of analyte atoms to the number of carrier gas atoms in the focal volume would have been decreased (dilution effect), which may result with reduced line intensities.

Plasma diagnostics in the presence of different background gases is an active area of research in LIBS. The type and amount of the background gas can have different effects on temperature, electron number density and excitation conditions of the plasma [33,38]. Singh et al. [33] have observed different temporal emission behaviours for As and $\mathrm{Sn}$ hydrides in the presence of $\mathrm{N}_{2}$ and He environment. Laserinduced breakdown spectroscopic detection of chemical hydrides in the presence of different background gases needs to be studied in detail for quantitative analysis.

\subsubsection{Efficiency of hydride generation}

The hydride generation efficiency of HG-LIBS sytem under optimum chemical conditions was determined from the measurement of analyte concentration in the waste liquid by ICP-MS. It was found that higher than $99 \%$ of the analyte was recovered into the gaseous phase while lower than $1 \%$ of the analyte remained in the waste liquid. 
(a)

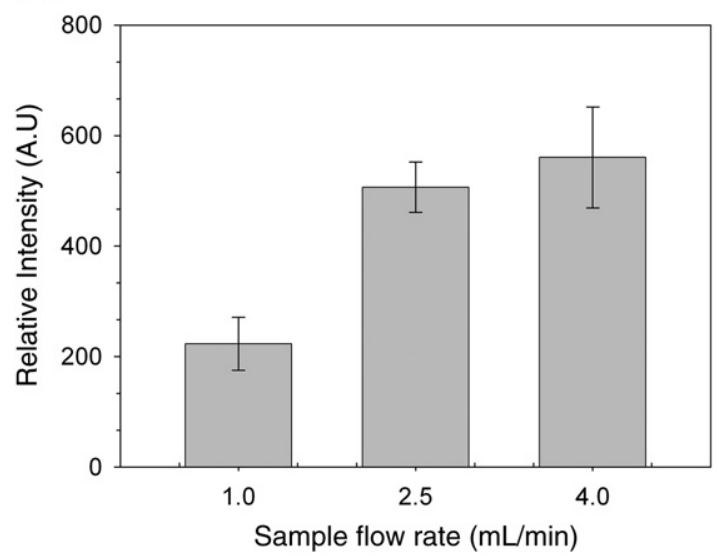

(b)

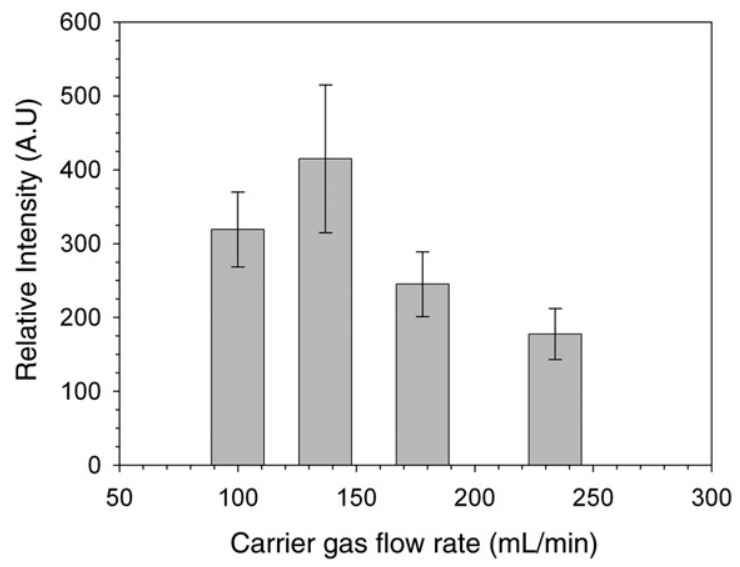

Fig. 6. Effect of sample flow rate (a) and carrier gas flow rate (b) on determination of tin by HG-LIBS. Accumulation of 10 laser shots, $150 \mathrm{~mJ} /$ pulse energy, Td: $10 \mu \mathrm{s}, \mathrm{Tg}: 3 \mathrm{~ms}$ and $5.0 \mathrm{mg} / \mathrm{L}$ Sn solution in $1.0 \%(\mathrm{v} / \mathrm{v}) \mathrm{HCl}$ were used. $5.0 \%(\mathrm{w} / \mathrm{v}) \mathrm{NaBH}_{4}$ in $1.0 \%(\mathrm{w} / \mathrm{v})$ $\mathrm{NaOH}$ and carrier gas $\left(\mathrm{N}_{2}\right)$ flow rate of $137 \mathrm{~mL} / \mathrm{min}$ were used.

\subsection{Effect of using membrane drying unit, MDU, on Sn signal intensity}

Removal of water content from the volatile hydrides is a common approach employed in HG sample introduction technique as it improves the sensitivity of the technique. Among several desolvation techniques [1], use of naphion membrane desolvating unit, MDU, for the removal of humidity is recently becoming more popular. In principle, a dry purge gas, $\mathrm{N}_{2}$ or Ar flows over the exterior surface of the membrane tubing, while wet gas (hydrides in this case) flows in a

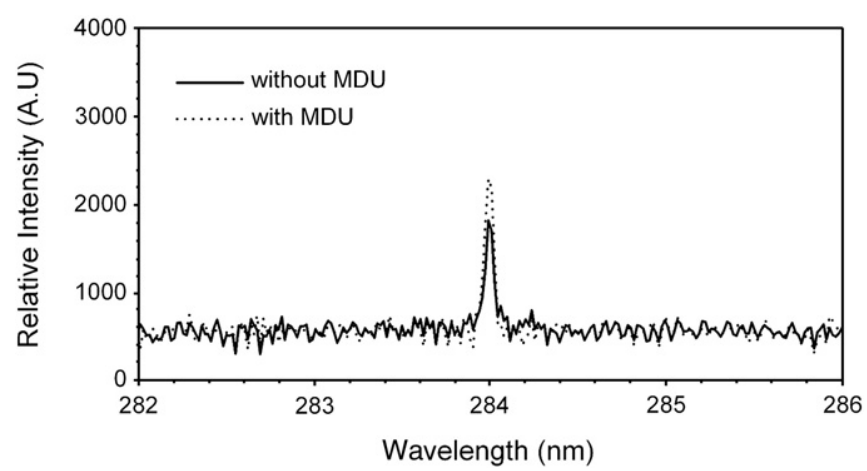

Fig. 7. The effect of membrane drying unit on Sn(I) signal intensity at $284.0 \mathrm{~nm}$, under optimum hydride generation condititons. $30 \%$ enhancement in $\mathrm{S} / \mathrm{N}$ was obtained when drying unit was used.
Table 2

Effect of using membrane desolvating unit, MDU, on LIBS signal.

\begin{tabular}{llll}
\hline & S/N* & \% RSD & \\
\cline { 3 - 4 } & & BG & Signal \\
\hline Without dryer & 24.37 & 22.98 & 43.29 \\
With dryer & 31.61 & 24.38 & 19.24 \\
Enhancement & $30 \%$ & & \\
\hline
\end{tabular}

Data is from eight single laser shots of $150 \mathrm{~mJ} /$ pulse energy. Signal is defined as the peak area under $284.0 \mathrm{~nm} \mathrm{Sn}(\mathrm{I})$ line minus the background intensity, BG. Noise was defined as three times the standard deviation of the background intensity.

counter-current direction inside the tubing (see Fig. 2). The water from the gaseous hydrides is extracted by the humidity gradient between the inside and outside of the tubing. We have used $\mathrm{N}_{2}$ as a purge gas with flow rates less than the carrier gas flow rate. The effect of membrane drying unit on tin signal intensity was shown in Fig. 7 and also \% RSD values of the analyte and the background signal with and without MDU were given in Table 2.

More than 50\% decrease in RSD value of the signal was obtained with the use of a membrane desolvating unit while RSD of the background, BG, does not change much. This enhancement in RSD of the signal corresponds to $30 \%$ enhancement in signal to noise ratio. Data were obtained from eight single laser shots of $150 \mathrm{~mJ} /$ pulse energy. Signal is defined as the peak area under $284.0 \mathrm{~nm} \mathrm{Sn(I)} \mathrm{line}$ minus the background intensity. Noise was defined as three times the standard deviation of the background intensity.

\subsection{Calibration graph for $\mathrm{Sn}$}

Under optimum conditions given in Table 1, a calibration graph was constructed for $284.0 \mathrm{~nm}$ neutral emission line of $\mathrm{Sn}(\mathrm{I})$ at various concentrations and presented in Fig. 8. Each point in the graph represents average peak area of seven sequential samplings for the concentration range of $1.0-75.0 \mathrm{mg} / \mathrm{L}$ tin. System has been washed between samplings of different concentrations with continuously flowing $\mathrm{NaBH}_{4}$ and acid solutions until no tin signal was observed, in order to avoid contamination. As can be seen from the figure that, there is a linear increase in LIBS signal upto $20.0 \mathrm{mg} / \mathrm{L}$ tin concentration and a linear fit to the data passes from the origin with a regression constant of $R^{2}=0.9989$. After $20.0 \mathrm{mg} / \mathrm{L}$, deviation from the linearity is observed. The regression constant decreases to $R^{2}=0.9843$ when data at $50.0 \mathrm{mg} / \mathrm{L}$ is included in regression analysis. This loss in sensitivity with increased concentration might be due to self absorption of the $\mathrm{Sn}(\mathrm{I})$ resonance line at $284.0 \mathrm{~nm}$. However, after $50.0 \mathrm{mg} / \mathrm{L}$ concentration signal intensity drastically decreases. In LIBS measurements, the loss of sensitivity due to self absorbed lines

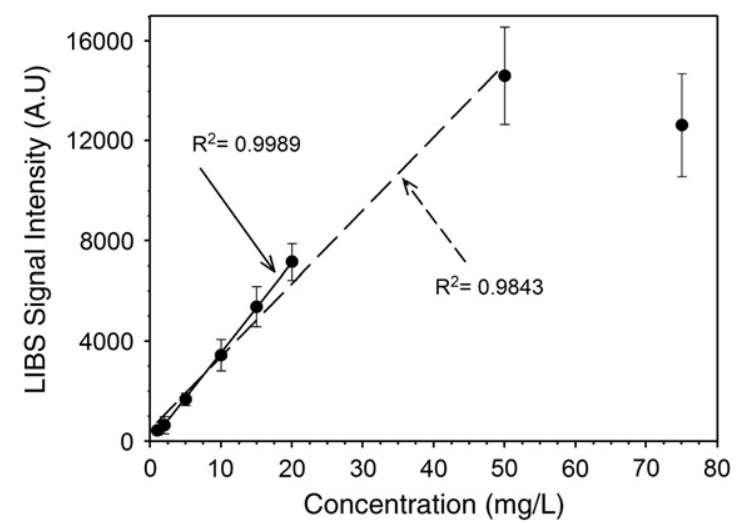

Fig. 8. Calibration graph for $\mathrm{Sn}(\mathrm{I})$ at $284.0 \mathrm{~nm}$ from chemically generated hydrides. Data represents average of seven replicate measurements each from the accumulation of 10 single laser shots. Td: $10 \mu \mathrm{s}$, Tg: $3 \mathrm{~ms}$, laser energy $150 \mathrm{~mJ} /$ pulse, $1.0 \%(\mathrm{v} / \mathrm{v}) \mathrm{HCl}: 2.5 \mathrm{~mL} /$ min, and $5.0 \%(\mathrm{w} / \mathrm{v}) \mathrm{NaBH}_{4}$ in $1.0 \% \mathrm{NaOH}: 5.0 \mathrm{~mL} / \mathrm{min}$ were used. 
Table 3

Recovery results from real water samples spiked with $10.0 \mathrm{mg} / \mathrm{L}$ Sn standard solution. Results are from the average of seven replicate measurements.

\begin{tabular}{ll}
\hline & \% Recovery \pm SD \\
\hline River water (SLRS-4) & $91.4 \pm 10.0$ \\
Tap water (Urla municipal water) & $94.1 \pm 16.3$ \\
Drinking water (spring water, Aydın) & $96.4 \pm 12.1$ \\
\hline
\end{tabular}

generally exhibits a levelling off in signal strength rather than a drop down. Therefore, this drastic decrease in signal strength at relatively large concentrations may be attributed to the inefficencies in hydride generation conditions. It appears that, chemical conditions of hydride generation, e.g. $\mathrm{NaBH}_{4}$ and $\mathrm{HCl}$ concentrations, need to be reoptimized for samples with tin concentrations higher than $50.0 \mathrm{mg} / \mathrm{L}$.

Based on $3 \sigma$ criterion, the detection limit (LOD) was determined as $0.3 \mathrm{mg} / \mathrm{L}$. That corresponds to about 300 times enhancement in sensitivity compared to the literature data [31] that employs a common sample introduction method for LIBS analysis of $\mathrm{Sn}$ in aqueous samples.

\subsection{Application to the real water samples}

In order to test the applicability of HG-LIBS method to the quantitative determination of $\mathrm{Sn}$ in aqueous environments, real water samples ingested with standard Sn solution were analyzed. For this purpose, $10.0 \mathrm{mg} / \mathrm{L}$ Sn standard solutions were spiked into bottled water, tap water and river water (SLRS-4) and analyzed under optimized instrumental and chemical conditions. Results, listed in the Table 3, clearly indicate over $90 \%$ recoveries for all types of real water samples being $91.4 \%, 94.1 \%$ and $96.4 \%$ for river, tap and drinking water samples, respectively. Water samples were tested for Sn content by HG-LIBS system before spiking but no detectable Sn concentration was observed.

\section{Conclusions}

A continuous flow HG-LIBS system for the analysis of volatile hydride forming elements in aqueous environments has been designed, constructed and optimized. Compared to batch type systems this continuous flow system provides constant sample and reagent flow through the atomization cell, which in turn results with fairly constant LIBS signal, within shot to shot fluctuation range of the laser used. Although, the detection power and sensitivity of LIBS measurements are still at low levels compared to other atomic spectrometric methods that use hydride generation as a sample introduction technique, however, the analytical results obtained from HG-LIBS experiments so far are found to be suitable for the analysis of $\mathrm{Sn}$ in aqueous environments in the form of tin (IV) hydride, stannane, $\mathrm{SnH}_{4}$. In order to obtain optimum hydride yield and reproducible LIBS signal, reaction conditions for Sn hydride were optimized. Optimum $\mathrm{NaBH}_{4}$ and $\mathrm{HCl}$ concentrations were determined as $2.0 \%(\mathrm{w} / \mathrm{v})$ and $1.0 \%(\mathrm{v} / \mathrm{v})$ at a flow rate of $5.0 \mathrm{~mL} / \mathrm{min}$ and $2.5 \mathrm{~mL} / \mathrm{min}$, respectively. A detection limit of $0.3 \mathrm{mg} / \mathrm{L}$, based on three times the standard deviation of the background, has been measured from standard Sn samples, by utilizing neutral tin, Sn(I), emission line at $284.0 \mathrm{~nm}$. Moreover, HG-LIBS sensitivity can be enhanced more by using element specific single channel detectors, like PMT.

Use of the membrane dryer between the GLS and the sample cell has provided $30 \%$ enhancement in $\mathrm{S} / \mathrm{N}$. Recoveries in the range of 91$96 \%$ were obtained from spiking experiments to real water samples.

Our future work will be on the application of the technique for the determination of other volatile hydride forming elements that pose a great danger to aquatic systems such as $\mathrm{As}, \mathrm{Cd}$ and $\mathrm{Pb}$ at $\mu \mathrm{g} / \mathrm{L}$ levels of concentration.

\section{Acknowledgements}

Authors thank IYTE and the Scientific and Technological Research Council of Turkey, TÜBITAK, for financial support through research projects: BAP-12, $108 \mathrm{~T} 376$ and $109 \mathrm{~T} 327$.

\section{References}

[1] J. Dedina, D. Tsalev, Hydride Generation and Atomic Absorption Spectrometry, Wiley and Sons, New York, 1995.

[2] P. Pohl, Hydride generation - recent advances in atomic emission spectrometry, Trends Anal. Chem. 23 (2004) 87-101.

[3] S. Yalcin, X.C. Le, Low pressure chromatographic separation of inorganic arsenic species using solid phase extraction cartridges, Talanta 47 (1998) 787-796.

[4] I.B. Karadjova, L. Lampugnani, M. Onor, A. D'Ulivo, D.L. Tsalev, Continuous flow hydride generation-atomic fluorescence spectrometric determination and speciation of arsenic in wine, Spectrochim. Acta Part B 60 (2005) 816-823.

[5] P. Viñas, I. López-Garcia, B. Merino-Meroño, N. Campillo, M. Hernádez-Córdoba, Liquid chromatography-hydride generation-atomic absorption spectrometry for the speciation of tin in seafoods, J. Environ. Monitor. 6 (2004) 262-266.

[6] X.C. Le, X.-F. Li, V. Lai, M. Ma, S. Yalcin, J. Feldmann, Simultaneous speciation of selenium and arsenic using elevated temperature liquid chromatography separation with inductively coupled plasma mass spectrometry detection, Spectrochim. Acta Part B 53 (1998) 899-909.

[7] Zhong-Xi Li, Yue-an Guo, Simultaneous determination of trace arsenic, antimony, bismuth and selenium in biological samples by hydride generation-four-channel atomic fluorescence spectrometry, Talanta 65 (2005) 1318-1325.

[8] W. Holak, Gas-sampling technique for arsenic determination by atomic absorption spectrophotometry, Anal. Chem. 41 (1969) 1712-1713.

[9] S. Farias, R.E. Rodriguez, A. Ledesma, D.A. Batistoni, P. Smichowski, Assessment of acid media effects on the determination of tin by hydride generation-inductively coupled plasma atomic emission spectrometry, Microchem. J. 73 (2002) 79-88.

[10] L.H.J. Lajunen, P. Perämäki, Spectrochemical Analysis by Atomic Absorption and Emission, 2nd ed., RSC, Cambridge, 2004, pp. 325-326.

[11] M. Krachler, H. Emonsb, C. Barbante, G. Cozzi, P. Cescon, W. Shotyk, Inter-method comparison for the determination of antimony and arsenic in peat samples, Anal. Chim. Acta 458 (2002) 387-396.

[12] L.J. Radziemski, D.A. Cremers, Laser-Induced Plasmas and Applications, Marcel Dekker, New York, 1989.

[13] W. Miziolek, V. Palleschi, I. Schechter (Eds.), Laser-Induced Breakdown Spectroscopy: Fundamentals and Applications, Cambridge University Press, 2006.

[14] D.A. Cremers, L.J. Radziemski, Handbook of Laser-Induced Breakdown Spectroscopy, Wiley, 2006

[15] J. Cunat, F.J. Fortes, J.J. Laserna, Real time and in situ determination of lead in road sediments using a man-portable laser-induced breakdown spectroscopy analyzer, Anal. Chim. Acta 633 (2009) 38-42.

[16] P.A. Mosier-Boss, S.H. Lieberman, Detection of lead derived from automotive scrap residue using a direct push fiber-optic laser-induced breakdown spectroscopy metal sensor, Appl. Spectrosc. 59 (2005) 1445-1456.

[17] D.A. Cremers, M.J. Ferris, M. Davies, Transportable laser-induced breakdown spectroscopy (LIBS) instrument for field-based soil analysis, P. Soc. Photo-Opt. Ins. 2835 (1996) 190-200.

[18] O. Samek, D.C.S. Beddows, J. Kaiser, S.V. Kukhlevsky, M. Liska, H.H. Telle, J. Young Application of laser-induced breakdown spectroscopy to in situ analysis of liquid samples, Opt. Eng. 39 (2000) 2248-2262.

[19] A. De Giacomo, M. Dell'Aglio, O. De Pascale, Single pulse-laser induced breakdown spectroscopy in aqueous solution, Appl. Phys. A 79 (2004) 1035-1038.

[20] D.A. Cremers, L.J. Radziemski, T.R. Loree, Spectrochemical analysis of liquids using the laser spark, Appl. Spectrosc. 38 (1984) 721-729.

[21] R. Knopp, F.J. Scherbaum, J.I. Kim, Laser Induced Breakdown Spectroscopy (LIBS) as an analytical tool for the detection of metal ions in aqueous solutions, Fresenius' J. Anal. Chem. 355 (1996) 16-20.

[22] P. Fichet, P. Mauchien, J.F. Wagner, C. Moulin, Quantitative elemental determination in water and oil by laser induced breakdown spectrometry, Anal. Chim. Acta. 429 (2001) 269-278.

[23] H.A. Archontaki, S.R. Crouch, Evaluation of an isolated droplet sample introduction system for laser-induced breakdown spectroscopy, Appl. Spectrosc. 42 (1988) 741-746.

[24] C. Janzen, R. Fleige, R. Noll, H. Schwenke, W. Lahmann, J. Knoth, P. Beaven, E. Jantzen, A. Oest, P. Koke, Analysis of small droplets with a new detector for liquid chromatography based on laser-induced breakdown spectroscopy, Spectrochim. Acta Part B 60 (2005) 993-1001.

[25] W.F. Ho, C.W. Ng, N.H. Cheung, Spectrochemical analysis of liquids using laser induced plasma emission: effects of laser wavelength, Appl. Spectrosc. 51 (1997) 87-91.

[26] W. Pearman, J. Scaffidi, S.M. Angel, Dual-pulse laser-induced breakdown spectroscopy in bulk aqueous solution with an orthogonal beam geometry, Appl. Opt. 42 (2003) 6085-6093.

[27] M. Lawrence-Snyder, J. Scaffidi, S.M. Angel, A.P.M. Michel, A.D. Chave, Sequentialpulse laser-induced breakdown spectroscopy of high-pressure bulk aqueous solutions, Appl. Spectrosc. 61 (2007) 171

[28] www.atsdr.cdcc.gov/toxprofiles/tp55.

[29] Jorge Moreda-Piñeiro, Purificación López-Mahia, Soledad Muniategui-Lorenzo, Esther Fernández-Fernández, Dario Prada-Rodriguez, Tin determination in 
marine sediment, soil, coal fly ash and coal slurried samples by hydride generation-electrothermal atomic absorption spectrometry, Anal. Chim. Acta 461 (2002) 261-271.

[30] X.C. Le, W.R. Cullen, K.J. Reimer, I.D. Brindle, A new continuous hydride generator for the determination of arsenic, antimony, and tin by hydride generation atomic absorption spectrometry, Anal. Chim. Acta 258 (1992) 307-315.

[31] Yong-Lai Feng, Hisatake Narasaki, Determination of tin in marine materials by using HG-HR-ICPMS, Talanta 46 (1998) 1155-1162.

[32] P. Fichet, P. Mauchien, J.F. Wagner, C. Moulin, Quantitative elemental determination in water and oil by laser induced breakdown spectroscopy, Anal. Chim. Acta 429 (2001) 269-278.

[33] J.P. Singh, H. Zhang, F. Yueh, K.P. Carney, Investigation of the effects of atmospheric conditions on the quantification of metal hydrides using laserinduced breakdown spectroscopy, Appl. Spectrosc. 50 (1996) 764-773.
[34] S. R. Kunati, Trace measurements of Tellurium, Tin and other metals by Atomic and Laser Spectroscopy Techniques, MSc Thesis, Youngstown State University, USA, 2008.

[35] E.A.P. Cheng, R.D. Fraser, J.G. Eden, Detection of trace concentrations of column III and V hydrides by Laser-Induced Breakdown Spectroscopy, Appl. Spectrosc. 45 (1991) 949-952.

[36] J.E. Carranza, D.W. Hahn, Sampling statistics and considerations for single-shot analysis using laser-induced breakdown spectroscopy, Spectrochim. Acta Part B 57 (2002) 779-790.

[37] L.J. Radziemski, T.R. Loree, D.A. Cremers, N.M. Hoffman, Time-resolved laserinduced breakdown spectrometry of aerosols, Anal. Chem. 55 (1983) 1246-1252.

[38] S. Yalcin, D.R. Crosley, G.P. Smith, G.W. Faris, Influence of ambient conditions on the laser air spark, Appl. Phys. B 68 (1999) 121-130. 